\title{
Hábitos de compra y consumo alimentario en tiempos de COVID-19
}

\section{Purchase and consumptions food habits in times of COVID-19}

Fecha de recepción:

o1 Julio del 2020
Dena Ma. Camarena Gómez ${ }^{*_{1}}$, Lizbeth Salgado Beltrán², María Elena Robles Baldenegro³ y Alma Teresita Velarde Mendívil ${ }^{4}$
Fecha de aprobación: 29 Septiembre del 2020

1* Profesora-investigadora Departamento de Contabilidad, Universidad de Sonora.

Correo electrónico: dena.camarena@unison.mx . ORCID https://orcid.org/oooo-ooo1-6634-2626

2 Profesora-investigadora Departamento de Economía, Universidad de Sonora.

Correo electrónico: lizbeth.salgado@unison.mx. ORCID http://orcid.org/oooo-ooo1-8846-275X

3 Profesora-investigadora Departamento de Contabilidad, Universidad de Sonora.

Correo electrónico: maria.robles@unison.mx. ORCID https://orcid.org/oooo-00o3-3358-1342

4 Profesora-investigadora Departamento de Contabilidad, Universidad de Sonora.

Correo electrónico: alma.velarde@unison.mx . ORCID https://orcid.org/oooo-0oo3-4164-6433

\section{Resumen}

En los primeros meses de la contingencia sanitaria propiciada por el virus SRAS-CoV-2, en el territorio nacional se suspendieron actividades no esenciales en los sectores público, privado y social. Como consecuencia, buena parte de la población modificó sus actividades diarias, trastocado diversos aspectos de las personas, incluyendo aquéllos que tienen que ver con hábitos en la alimentación. En esta investigación se analizan los hábitos de compra y consumo alimentario de los consumidores mexicanos durante el confinamiento por COVID-19. Los hallazgos muestran que el $75.7 \%$ de los participantes modificaron sus hábitos de consumo alimentario, particularmente en la cena y desayuno. Productos de repostería, seguido de frutas y verduras fueron los que presentaron un mayor incremento en su consumo. Por otra parte, los hábitos de compra cambiaron para el $51.7 \%$ de los consumidores, eligiendo en mayor medida los establecimientos de supermercados o hipermercados para realizar sus compras. En la elección del establecimiento valoran en mayor medida las medidas de higiene, así como cuidado y protección de los empleados. En general, conocer las pautas de consumo y hábitos de compra alimentario en un escenario de crisis sanitaria, permiten generar estrategias orientadas al mercado que son fundamentales para la subsistencia de los establecimientos comerciales.
Palabras claves: Hábitos alimentarios, consumidores mexicanos, escala conciencia hacia la salud.

CÓDIGO JEL: D11, D12, M31.

\section{Abstract}

In the first months of the health contingency caused by the SARS-CoV-2 virus, non-essential activities in the public, private and social sectors are suspended in the national territory. As a consequence, a large part of the population modified their daily activities, disrupting various aspects of people, including those that have to do with eating habits. This research analyzes the purchasing and food consumption habits of Mexican consumers during confinement due to COVID-19. The results show that $75.7 \%$ of the participants modified their eating habits, particularly at dinner and breakfast. Pastry products, followed by fruits and vegetables, were those that presented a greater increase in their consumption. On the other hand, shopping habits changed for $51.7 \%$ of consumers, choosing to a greater extent supermarkets or hypermarkets to make their purchases. When choosing the establishment, they value hygiene measures to a greater extent, as well as care and protection of employees. In general, knowing the consumption behavior and food purchasing habits in a health 
crisis scenario, allowing the generation of marketoriented strategies that are essential for the subsistence of commercial establishments.

Key words: food habits, mexican consumers, health consciousness scale

JEL code: D11, D12, M31.

\section{Introducción}

La presencia del virus coronavirus SARSCoV-2 fue notificada por primera vez en Whuan China en diciembre de 2019, la enfermedad que ocasiona fue declarada como Pandemia por la Organización Mundial de la Salud el 11 de marzo del 2020 (WHO, 2020a). Desde entonces el número de personas confirmadas con el padecimiento de Covid-19 ha ido en aumento, estimándose para el mes de septiembre más de 35 millones de casos confirmados a nivel mundial. En el continente americano secentraactualmenteel 53.4\% delos casos confirmados, mientras que en el caso particular de México las cifras de 385 mil personas diagnosticadas con Covid-19 representan el 2.1\% del total mundial y corresponden al 4.4\% a nivel Latinoamérica (WHO, 2020b). Estas cifras dejan entrever el impacto global $y$ nacional que ha ocasionado la pandemia en términos de salud, sin embargo, las repercusiones van más allá y también afectan diversos aspectos de la vida cotidiana de las personas. A partir del 30 de marzo se acordaron medidas extraordinarias en todo el territorio nacional que conllevo a la suspensión de actividades no esenciales en los sectores público, privado y social, con el propósito de mitigar la dispersión y trasmisión del virus (Secretaria de Salud, 2020).

A partir de ese momento se implementan las estrategias de "Distanciamiento social" y el Plan de Contingencia "Quédate en casa" efectuadas como política pública sanitaria, significando para la población una restricción de movilidad y desplazamiento, reduciendo al extremo la coexistencia en las áreas de alto riesgo (áreas cerradas, alta densidad de personas, visitas a familiares, amigos, reuniones de cualquier tipo, etc.) y las actividades no prioritarias (deportes, viajes, cualquier tipo de actividad relacionada con la socialización, ocio, etc.) es decir, una interrupción que comprende la suspensión de ciertas actividades económicas, la reserva de congregaciones masiva acompañada de un agudo resguardo domiciliario, colocando a la población en un escenario de distanciamiento y confinamiento sin antecedentes.

A pesar de las medidas establecidas, la presencia de la epidemia se presentó en México por primera ocasión el 13 de enero del 2020 con el primer caso registrado, al 24 de febrero se reportaron siete casos. Para el día de la declaratoria del confinamiento (30 de marzo) ya se contabilizaban un total de casos acumulados de 1,645 pacientes con Covid-19 y a principios del mes de abril se reportaba por parte del gobierno federal 2,268 casos confirmados. A partir de este punto, la curva de comportamiento presentó un despunte exponencial alcanzando el 15 de mayo la cifra de 62,629 casos confirmados acumulados y un mes después, 186,178 según los reportes de la Secretaria de Salud. De acuerdo con lo publicado por el gobierno federal en sus plataformas oficiales, el día 20 de julio es cuando se alcanza el máximo de casos nuevos reportados con 8, 647 mismos que se reflejan en los ya para entonces, 395, 713 casos acumulados confirmados (Dirección General de Epidemiología, 2020).

La tendencia decreciente en el comportamiento de la epidemia Covid-19 en México, se presenta a partir del día 21 de julio, al presentar 366 casos menos que el día anterior. Aunque es importante recalcar que la curva de casos acumulados confirmados no ha dejado de presentar un crecimiento. A partir de ese día y a la fecha los reportes diarios a escala nacional han presentado una variación a la baja. Alcanzando su mínimo diario a la fecha del 28 de septiembre de 1,826 personas afectadas por la enfermedad, son 797,367 los acumulados y 81,033 las defunciones por causa del virus lo que ha impactado a miles de hogares a lo largo de la república (Idem).

Aunque a la fecha existen datos variables sobre el número de personas confinadas en México, la CEPAL (2020:29), menciona que “...las cuarentenas de alcance nacional son más efectivas para reducir la movilidad de las personas. Ello se confirma con la mayoría de los países que aplicaron esta medida con la excepción de Haití en donde la movilidad sólo se redujo en torno a un 30\%. Otros países en la que la movilidad no disminuyó en similar intensidad al resto, a pesar de las medidas implementadas, son Jamaica y México...,

La movilidad de la ciudadanía se ha visto modificada de manera importantedurantelos primeros meses de la contingencia parcial, sin embargo, son los meses 
intermedios - abril a junio - cuando la disminución en la movilidad es más pronunciada. Básicamente un $43 \%$ del total de mexicanos $(128,649312.95)$ redujeron su movilidad, su presencia en espacios públicos y eliminando o escalonando las actividades no esenciales.

Como consecuencia de todo lo anterior, distintas actividades que se realizaban de manera presencial empezaron a desarrollarse en modalidad en línea, algunas se suspendieron y en otros casos se efectuaron con nuevas medidas y condiciones como aforos reducidos, control de horarios, distancia de seguridad, entre otros. De tal manera que buena parte de la población modificó sus actividades diarias, propiciando una alteración en sus hábitos de consumo, compra y estilos de vida.

Por otra parte, el crecimiento del sector empresarial a nivel nacional desde el 2009 - 2019, mostraba un crecimiento marcado, sin embargo, el impacto de las acciones llevadas a cabo durante la contingencia sanitaria ha repercutido directamente en la dinámica empresarial y en la generación de empleos. De un total de 1,873,564 empresas, 224, 296 solicitaron créditos o financiamiento de emergencia y en torno a 1, 115, 983 instrumentaron paros técnicos o cierres temporales ante la eventualidad originada por el Covid-19 (INEGI, 2020a).

En esteescenario, las empresas tuvieron queajustarse y en algunos casos "reinventarse" a nuevos esquemas de operación como el trabajo remoto, operaciones de compraventa en línea, reducciones de horarios, limitación de visitas de clientes o aforo, cambio de giro empresarial, entre otros. Un gran número de empresas han sufrido pérdidas de ingresos, por lo que no resulta extraño que el financiamiento sea el apoyo más requerido y los ajustes en personal sea otra de las acciones recurrentes. En el mes de abril en torno a 32.9 millones de personas del país se encontraban desempleadas, de ese total un $92.9 \%$ se relacionaba con acciones derivadas del Covid-19. Como consecuencia un $65.1 \%$ de los hogares presentaron una reducción de sus ingresos (INEGI, 202ob).

Es así como la pandemia deja al descubierto una severa crisis económica. Algunos estudios prevén una contracción económica de $4.5 \%$ y una reducción en el PIB de entre el 2.5 y 6.0\% para el país en el 2020 (Amador et al., 2020; Gaytán, 2020). Básicamente a consecuencia de las medidas implementadas, de la situación económica y del entorno de salud, las diversas actividades que realizan los individuos se han visto claramente afectadas, una de ellas es la alimentación. Si bien, los establecimientos especializados en la venta de alimentos han continuado operando por ser considerados servicios esenciales, lo cierto es que acciones como salir a comer fuera del hogar, la disponibilidad y variedad de alimentos, los horarios reducidos para efectuar las compras, el nuevo contexto económico, entre otros han condicionado la compra y consumo de productos.

Al mismo tiempo, los sentimientos de angustia, aprensión-que habitualmente el 10\% de la población mundial padece en niveles altos (Zoccolini, 2014)-, con la crisis de salud se intensificaron. En algunos casos de manera individual, en otros de forma conjunta factores económicos, sociales $y$ del entorno conllevan a sufrimientos asociados a crisis de pánicos, fobias, ansiedad, entre otros, los cuales pueden repercutir directamente en la alimentación de los individuos. Por otra parte, la estrategia "Quédate en casa" también ha generado mayor disponibilidad de tiempo para elaborar y cocinar los alimentos, la convivencia familiar y la realización de comidas más elaboradas, también están aquéllos que buscan una alimentación sana o replicar platillos que se divulgan en redes sociales y medios de comunicación. En cualquiera de los casos es indudable que existen elementos del entorno que han influido en el consumidor y que dejan entrever que las conductas de compra y consumo alimentario de los individuos pueden haberse modificado. De ahí que el objetivo de esta investigación es analizar los hábitos de compra y consumo alimentario en tiempos de COVID-19.

\section{Marco Teórico}

Las investigaciones del área de ciencias sociales concernientes a la emergencia sanitaria por el COVID-19 son escasas con una tendencia al alza. Algunos de estos estudios se centran en el impacto de la pandemia en el sistema de medios de comunicación (Casero-Ripollés, 2020); comportamiento alimentario (Maraver-Romero 2020; García-Álvarez et al., 2020; Vergara-Castañeda; Laguna et al., 2020); crisis económica y financiera (Ortiz et al., 2020; Campos y Esquivel 2020; Baker et al., 2020; Andersen et al., 2020; Baldwin y Weder di Mauro, 2020 inter alia) con resultados preliminares. 
Sobre el comportamiento alimentario, autores como Maraver-Romero (2020) sugiere que la dieta mediterránea tendrá un importante papel en la lucha contra el COVID, al incrementar el sistema inmunitario. Laguna et al. (2020), encontraron que los consumidores españoles incrementaron el consumo en productos como la leche, huevo, vegetales frescos, pan, carnes etc. y redujeron la compra en alcohol, comida lista para consumir, postres, productos de panadería, sopas instantáneas entre otros, durante el confinamiento, relacionándolo con motivadores de mejora de la salud. Por otro lado, García Álvarez et al., (2020) asocian un posible aumento en el consumo de tabaco y alcohol como respuesta emocional negativa a la situación de confinamiento.

Sobre el comportamiento del consumidor mexicano, los consumidores esperan reducir su frecuencia de viajes, visitas a centros comerciales y eventos sociales después de COVID (Mckinsey and Company, 2020). La preferencia por tiendas online mantuvo una tendencia creciente durante los meses de contingencia, con un porcentaje doblemente más altoqueal inicio, seposicionócomounodeloscanales con mayor crecimiento, así el uso de plataformas de servicios de entrega (delivery) también se ha incrementado, siendo las personas más jóvenes y las del NSE-C las que principalmente han comenzado a preparar sus propios alimentos, mientras que a mayor nivel socioeconómico se incrementó el uso de servicios de entrega a domicilio (AtlantiaSearch, 2020). En esta línea, la Asociación Mexicana de Ventas Online (2020) detalla que las tres principales razones por las que los consumidores prefieren comprar en línea son: el $55 \%$ de las personas no quiere salir de su casa por la contingencia, $48 \%$ quiere evitar las aglomeraciones en tiendas físicas y un $35 \%$ de los consumidores indican que en internet han encontrado más y mejores ofertas.

También se observa que la alta volatilidad de la demanda está provocando un cambio de marcas (Entrepeneur, 2020), el 46\% de los consumidores han probado otras opciones, impulsados por la falta de disponibilidad de sus productos habituales, aunque sólo el $9 \%$ cambiará su preferencia al terminar la contingencia (Mckinsey and Company, 2020). Por el contrario del canal de compra, el 72 $\%$ de las personas que han comprado o pagado, por primera vez, un servicio a través de internet seguirá usando está vía al terminar el confinamiento (Asociación Mexicana de Ventas Online, 2020).
En general, en el ámbito nacional se están generando investigaciones con distintas perspectivas, desde la visión de la demanda de alimentos todavía son escasas. De ahí, que esta investigación busque cubrir ese vacío en la literatura y aporte los elementos para conocer el impacto que la contingencia sanitaria ha tenido en los hábitos y compra de alimentos de los consumidores mexicanos.

\section{Metodología}

Para alcanzar el objetivo general se realizó una investigación empírica con consumidores mexicanos. Se realizó una encuesta dirigida a consumidores mayores de 18 años, utilizándose el método no probabilístico de bola de nieve, el cual se define como una técnica para encontrar al objeto de investigación donde un sujeto le da al investigador el nombre de otro, que a su vez proporciona el nombre de un tercero, y así sucesivamente (Atkinson y Flint, 2001). Es decir, se detectan las unidades muestrales a través de redes directas e indirectas del investigador y el objeto de estudio (Baltar y Gorjup, 2012). Con este método, se lograron obtener 867 encuestas de personas que residen en México. La recopilación de la información se llevó a cabo del 17 al 24 de mayo del 2020 en línea por medio de la plataforma Google Forms. Antes de su aplicación se realizaron diversas pruebas piloto con el fin de conseguir una comprensión de todos los reactivos incluidos e identificar y resolver cualquier dificultad técnica que pudiera presentar al momento de responder la encuesta.

Los datos se analizaron en el programa SPSS versión 21.0, calculándose estadísticos descriptivos, se utilizaron la frecuencia, la media y la mediana con la finalidad de comparar los resultados entre los grupos de variables.

\section{Resultados y Discusión}

Los hallazgos de la investigación, muestran que en el rango de los 18-25 años se concentra la mayor proporción de la muestra con el 31.6\%, seguido por aquellos que se encuentran en el tramo de 41-45 años de edad con el 13.8\%. En la distribución del sexo, los hombres representaron el $31.8 \%$ y las mujeres el $68.2 \%$. En lo que respecta al ingreso mensual, el $21.5 \%$ se ubica en la categoría de \$5,000-10,000 pesos mensuales, que de acuerdo con 
la regla de AMAI las personas se encuentran dentro del Nivel Socioeconómico (NSE) C, C+ media alta (AMAI, 2018). El 58.4\% cuenta con estudios universitarios, mientras que el $1.3 \%$ sólo tiene hasta secundaria. La mayor proporción son empleados de gobierno (18.0\%), seguidos de empleados en empresa privada y estudiante, con un 22.0 y $23.9 \%$, respectivamente (Tabla 1 ).

En relación con su alimentación, el $75.7 \%$ de los participantes considera que ha modificado su hábitos alimentarios durante el período de confinamiento. Es el desayuno donde se han presentado menos cambios y se mantiene igual que siempre (38.1\%), en el almuerzo ha sufrido en mayor medida una modificación parcial (36.1\%), mientras que un $40.4 \%$ considera una modificación completa en la cena. Es posible que estos cambios se relacionen con la disponibilidad de tiempo para preparar los alimentos en el hogar, el dejar de salir a cenar fuera o bien la compra de alimentos a domicilio (Tabla 2).
Entre los motivos de cambio en la alimentación, el tiempo es un elemento clave, la permanencia en el hogar ha llevado a mayor disposición para elaborar las distintas comidas, probar recetas o hacer aquellos platillos que conllevan mayor elaboración en tiempo. Si bien existen estudios que están relacionando el estrés o ansiedad ocasionada por el confinamiento que lleva a las personas a cambiar sus hábitos de consumo, en esta investigación fue el segundo motivo, pero la valoración se encuentra escasamente por encima de la media (2.6 en una escala de cinco puntos). Los motivos orientados a mejorar la salud como la dieta para controlar peso tienen una media de 2.3 y los motivos de salud (2.2), lo cual sugiere que los individuos aún no están listos para hacer una modificación en este sentido (Tabla 3) y se evidencia con los alimentos en los que han incrementado su consumo (Gráficar).

Tabla 1. Características socio demográficas y económicas de la muestra

\begin{tabular}{cccccccc}
\hline Edad & $\%$ & Nivel de estudios & $\%$ & Ingresos & $\%$ & Actividad & $\%$ \\
\hline $18-25$ & 31.6 & Primaria & 0.3 & Menos de 5 mil & 22.5 & $\begin{array}{c}\text { Estudiante } \\
\text { Empleado empresa } \\
\text { privada }\end{array}$ & 22.9 \\
\hline $26-30$ & 10.7 & Secundaria & 1.0 & 5 -10 mil & 21.5 & 15.0 \\
\hline $31-35$ & 9.0 & Bachillerato & 12.0 & $11-15$ & 15.6 & $\begin{array}{c}\text { Empleado gobierno } \\
18.0\end{array}$ \\
\hline $36-40$ & 6.5 & Técnicos & 1.2 & $16-20$ & 11.6 & El hogar & 9.2 \\
\hline $41-45$ & 13.8 & Universitarios & 58.4 & $21-25$ & 8.4 & $\begin{array}{c}\text { Empresario/a } \\
\text { Profesional }\end{array}$ & 5.2 \\
\hline $46-50$ & 9.6 & Maestría & 18.3 & $26-30$ & 5.7 & independiente & 18.3 \\
\hline $51-55$ & 8.7 & Doctorado & 8.3 & $31-35$ & 4.5 & Actualmente no trabajo & 3.3 \\
\hline $56-60$ & 7.6 & Sexo & $\%$ & $36-40$ & 3.0 & & \\
\hline $61-70$ & 2.4 & Hombre & 31.8 & Más de 41 mil & 7.3 & & \\
\hline 70 y más & 0.1 & Mujer & 68.2 & & & & \\
\hline
\end{tabular}

Elaboración propia

Tabla 2. Grados de modificación en las comidas

\begin{tabular}{cccc}
\hline & $\begin{array}{c}\text { Se mantiene igual que } \\
\text { siempre (\%) }\end{array}$ & $\begin{array}{c}\text { Se ha modificado } \\
\text { parcialmente (\%) }\end{array}$ & $\begin{array}{c}\text { Se ha modificado } \\
\text { completamente (\%) }\end{array}$ \\
\hline Desayuno & 38.1 & 29.5 & 32.8 \\
Comida/ almuerzo & 32.3 & 36.5 & 26.8 \\
Cena & 29.6 & 34.0 & 40.4 \\
\hline
\end{tabular}

Elaboración propia 
Tabla 3. Motivos de cambios en la alimentación

\begin{tabular}{|c|c|c|c|c|c|}
\hline Ítems & $\begin{array}{l}\text { Valores } \\
\text { medios }\end{array}$ & Desv. Tip. & Ítems & $\begin{array}{l}\text { Valores } \\
\text { medios }\end{array}$ & Desv. Tip. \\
\hline $\begin{array}{c}\text { Mayor disponibilidad de tiempo } \\
\text { para elaborar las comidas }\end{array}$ & 3.7 & 1.442 & Otros & 2.1 & 1.518 \\
\hline Estrés o ansiedad & 2.6 & 1.465 & Situación económica & 2.0 & 1.256 \\
\hline Dieta para el control de peso & 2.3 & 1.489 & $\begin{array}{l}\text { Falta de tiempo para } \\
\text { cocinar }\end{array}$ & 1.7 & 1.220 \\
\hline Motivos de salud & 2.2 & 1.420 & Escasez de alimentos & 1.7 & 1.120 \\
\hline
\end{tabular}

Elaboración propia

Los alimentos en los cuales ha incrementado su consumo destacan la repostería (13.4\%), frutas $(12.5 \%)$ y verduras (12.1\%), así como botanas o aperitivos (10.4\%). Hay que considerar que tanto la repostería como las botanas pueden considerarse como alimentos escasamente nutritivos (Gráfica 1). En el caso de las bebidas alcohólicas su escaso consumo (2.2\%) tiene relación con la medida sobre la prohibición de consumo y venta de bebidas con contenido alcohólico que se implementó en diversos estados del país.

En lo relativo a los hábitos de compra de alimentos el $51.7 \%$ considera que se han modificado y el $48.3 \%$ que han cambiado parcialmente. Las compras durante la contingencia se han realizado en mayor medida en supermercados o hipermercados, con un valor medio de 4.2 en una escala de 5 puntos. Le siguen las tiendas o abarrotes de barrio (3.0) y las tiendas de conveniencia (2.9). Es posible que exista una relación con el tipo de distribución, ya que estos establecimientos cuentan con cadenas de suministros más robustas y algunos disponen de ventas en línea que facilitan la compra. Al mismo tiempo, se advierte un claro detrimento de tianguis, establecimientos gourmet o compras efectuadas directamente con el productor, estos resultados coinciden con la investigación realizada por AtlantiaSearch (2020), donde estos canales tuvieron menos relevancia (Tabla 4).

\section{Gráfica 1. Alimentos que han incrementado el consumo}

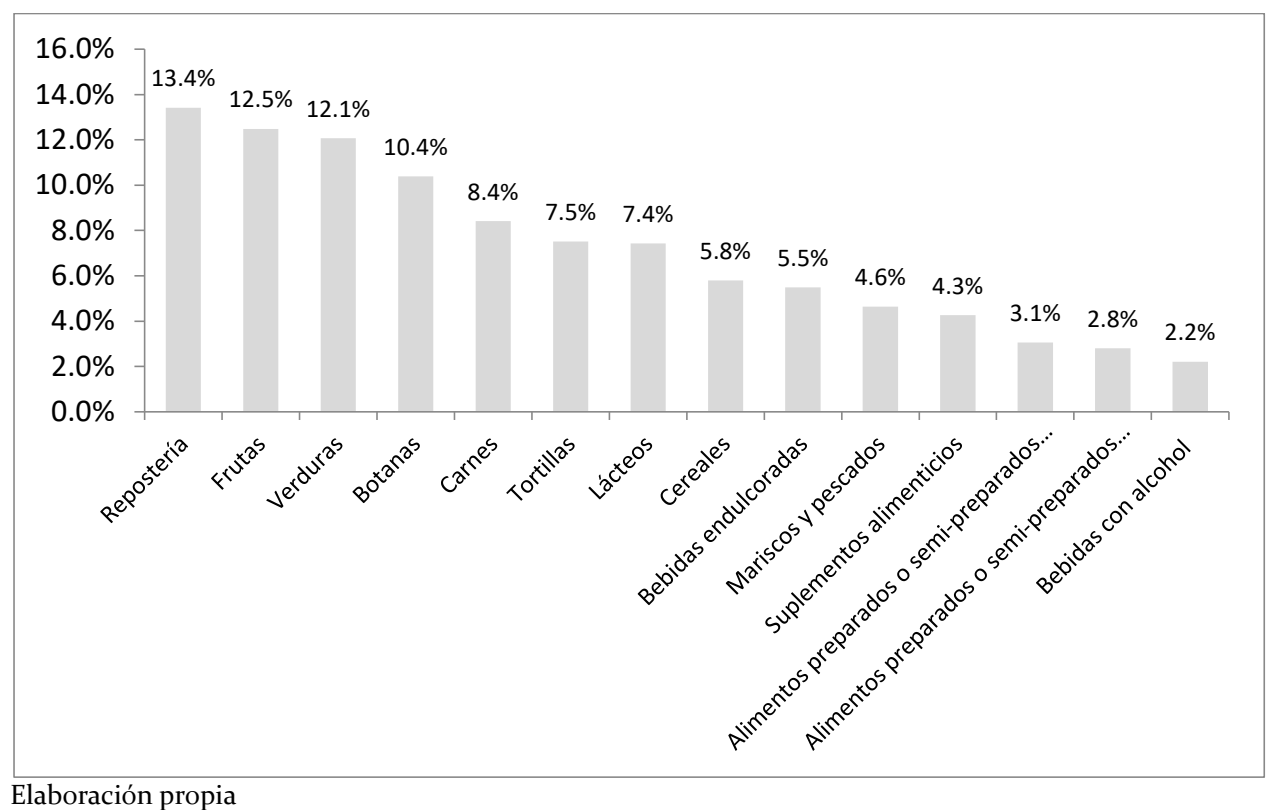


Tabla 4. Compras en establecimientos

\begin{tabular}{|c|c|c|c|c|c|}
\hline Establecimiento & $\begin{array}{l}\text { Valores } \\
\text { medios }\end{array}$ & Desv. Tip. & Establecimiento & $\begin{array}{l}\text { Valores } \\
\text { medios }\end{array}$ & Desv. Tip. \\
\hline $\begin{array}{l}\text { Supermercado o } \\
\text { hipermercado }\end{array}$ & 4.2 & 1.263 & $\begin{array}{c}\text { Directamente del } \\
\text { productor }\end{array}$ & 1.6 & 1.192 \\
\hline $\begin{array}{c}\text { Tienda o abarrotes de } \\
\text { barrio }\end{array}$ & 3.0 & 1.581 & Tiendas gourmet & 1.5 & 1.010 \\
\hline Tiendas de conveniencia & 2.9 & 1.483 & Otro & 1.4 & 1.102 \\
\hline Mercado tradicional & 2.2 & 1.516 & Tianguis & 1.3 & 0.944 \\
\hline Restaurantes & 1.8 & 1.156 & & & \\
\hline
\end{tabular}

Elaboración propia

$\mathrm{Al}$ indagar sobre los aspectos que más han tomado en consideración al efectuar las compras de alimentos, destacan las medidas de higiene con un valor medio de 4.2, seguido de cerca por los cuidados y protección de los empleados, así como la calidad de los productos con un valor de 4.1 cada uno. Llama la atención que el servicio a domicilio y las ventas por internet no estén dentro de los valores medios altos, lo cual sugiere que la higiene -en una situación de emergencia sanitaria-, es el atributo más valorado, incluso más que el precio de los artículos (Tabla 5).

\section{Conclusiones}

El confinamiento por la contingencia sanitaria COVID-19 que se decretó en México a partir del mes de marzo de 2020, ha generado impactos en la población en diversos aspectos de su vida cotidiana. Las cifras de los casos confirmados de Coronavirus han ido en aumento y con ello, las medidas que se establecen desde los gobiernos y desde la iniciativa personal. Como resultado, los estilos de vida se han visto afectados, generando en algunos casos adecuaciones y modificaciones no sólo de índole económica, social, psicológica y laboral, sino también en los hábitos de compra y consumo alimentario, así como en la percepción que se tiene hacia la salud.

En este contexto, se realizó una investigación dirigida a consumidores mexicanos con el propósito de analizar los hábitos de compra y consumo alimentario en tiempos de COVID-19. Los hallazgos muestran que la contingencia ha conducido a modificaciones en los comportamientos de compra de alimentos, ya que más de la mitad de los consumidores manifiesta que así ha sucedido (51.7\%). Las compras en súper e hipermercados priman sobre opciones como las tiendas o abarrotes de barrio, mercados, tianguis, entre otros. Los factores relacionados con las medidas de higiene,

Tabla 5. Valoración de aspectos en establecimientos

\begin{tabular}{|cccccc}
\hline Aspectos & $\begin{array}{c}\text { Valores } \\
\text { medios }\end{array}$ & Desv. tip. & Aspectos & $\begin{array}{c}\text { Valores } \\
\text { medios }\end{array}$ & $\begin{array}{c}\text { Desv. } \\
\text { tip. }\end{array}$ \\
\hline $\begin{array}{c}\text { Medidas de higiene } \\
\text { Cuidados y protección que utilizan } \\
\text { los empleados }\end{array}$ & 4.2 & 1.092 & Promociones y descuento & 3.5 & 1.399 \\
\hline $\begin{array}{c}\text { Calidad de los productos } \\
\text { Aspectos nutrimentales }\end{array}$ & 4.1 & 1.175 & El servicio a domicilio & 3.3 & 1.601 \\
\hline $\begin{array}{c}\text { La ubicación } \\
\text { Los precios }\end{array}$ & 3.9 & 1.143 & Control de aforo & 3.3 & 1.509 \\
\hline $\begin{array}{c}\text { La disponibilidad (oferta) de } \\
\text { productos }\end{array}$ & 3.9 & 1.295 & Que sea local o de la región & 3.0 & 1.565 \\
\hline La atención y servicio & 3.8 & 1.323 & Recomendaciones & 2.8 & 1.487 \\
\hline
\end{tabular}

Elaboración propia 
cuidado y seguridad han pasado a ser las más importantes para los consumidores al momento de tomar la decisión de comprar alimentos. Estas valoraciones tienen sentido si se consideran las recomendaciones emitidas por las autoridades de salud a toda la población, donde se hace énfasis en aspectos de higiene, distancia social y medidas de limpieza. Si bien, todos los establecimientos pueden respetar y cumplir estas directrices, lo cierto es que la capacidad de respuesta y la percepción de seguridad que se trasmite al consumidor pueden variar a favor de las grandes superficies. Contrario a lo que se esperaría, el servicio de venta en línea en los primeros meses de la pandemia no se consideró un factor decisivo al momento de elegir un establecimiento comercial.

Al mismo tiempo, tres cuartas partes de los consumidores reconocen que sus hábitos de consumo alimentario se han visto modificados durante la contingencia sanitaria y confinamiento. Las modificaciones se visualizan sobre todo al momento de preparar comida, ya que debido a la permanencia en el domicilio se dispone de mayor tiempo para cocinar, particularmente durante la cena. Esta tendencia se relaciona con aspectos económicos y las restricciones de horario, así como de cierre y apertura de los establecimientos, por lo que el comer fuera de casa es menos factible. De igual manera, aunque en menor medida, los cambios en la alimentación se atribuyen al estrés o ansiedad a la que se han visto sometidas las personas. Al respecto, la pérdida de familiares o enfermos por COVID-19, junto con el resguardo domiciliario que se ha prolongado por meses, ocasionan situaciones de estrés y ansiedad que influyen en el consumo alimentario de los individuos. Aunado a estos factores, también los aspectos económicos son claves en esta condición, tan sólo en el mes de abril 32.9 millones de personas en el país no disponían de empleo o contaban con una suspensión laboral, de los cuales el $\mathbf{9 2 . 9 \%}$ se relaciona de alguna manera con el COVID-19. A la par el 65.1\% de las viviendas reportaron una disminución de los ingresos como consecuencia de la pandemia (INEGI, 2020b).

De igual forma, no se debe perder de vista que condiciones de salud pueden influir en la alimentación de una persona. En el caso de México la incidencia de enfermedades crónico-degenerativas cobran un papel relevante en la salud y estilos de vida de la población, en 2018 el $75 \%$ de los adultos en el país padecía sobrepeso u obesidad, el $10 \%$ diabetes y el 18\% hipertensión (Âlvarez-López et al., 2020). Estas condicionantes tendrían que influir en la búsqueda de una alimentación más sana, si bien los resultados muestran que durante la contingencia sanitaria los consumidores manifiestan que el consumo de frutas y verduras se incrementó, 12.5 y $12.1 \%$ en cada caso, lo cierto es que son los productos de repostería los que presentaron un aumento más pronunciado (13.4\%). Estos datos no dejan de ser llamativos, ya que se esperaría que el consumo de alimentos menos saludables disminuyera como un "cuidado" adicional que toman las personas, sin embargo, es posible que otros factores relacionados con el precio y disponibilidad también influyan en las motivaciones para degustarlos.

En general, el contexto de contingencia de salud que se vive en el ámbito nacional ha tenido un efecto directo en los hábitos de compra y consumo alimentario. Sin lugar a duda para el consumidor, la búsqueda de una alimentación nutritiva es más importante, sin descuidar la calidad de los productos.

Desde una perspectiva empresarial, identificar las pautas de consumo y hábitos de compra alimentario son fundamentales para la subsistencia de los establecimientos comerciales, los cuales pueden diseñar estrategias donde se resalten aspectos relativosalasalud,cuidadoehigiene, particularmente en las pequeñas empresas que han sido las más afectadas durante esta pandemia. Es necesario recordar que la permanencia de las empresas es fundamental para la recuperación y dinamismo de la economía. De ahí que conocer al consumidor en tiempos de crisis, se vuelve más que nunca una pieza clave para el crecimiento empresarial. Desde el ámbito académico, eventos inesperados como la llegada del COVID-19, han dejado claro que la interconexión global es más evidente que nunca, que el conocimiento y aprendizaje es la clave para hacer frente a los retos que se presentan a la humanidad, y desde la particular visión de esta investigación conocer las actitudes, motivaciones y reacciones del consumidor contribuye a comprender las transformaciones y cambios que se presentan en situaciones de inseguridad e incertidumbre.

\section{Bibliografía}

Amador, J., Cervantes, D., Rodríguez, A. Aranzazu, S. y Serrano, C. (2020). Impacto del Covid-19 en 
la economía: la inacción es más peligrosa que la sobrerreacción, tanto para la salud pública como para la economía, Análisis Económico, BBVA research. Recuperado el o5 de octubre de 2020 de: https://www. bbvaresearch.com/publicaciones/mexico-impactodel-covid-19-en-la-economia-inaccion-es-maspeligrosa-que-sobrerreaccion/?cid=eml:oem:oth:---45425--:::lnkpubl:::20200325::oth:instant:

AMAI. (2018). Niveles socioeconómicos. 2018, de AMAI/ NSE. Recuperado en julio del 2020 en: http://nse. amai.org/data2018/.

Asociación Mexicana de Ventas Online (2020). Reporte 3.o Impacto COVID-19 en venta online en México. Recuperado en julio de 2020 en: https://www.amvo. org.mx/estudios/reporte-3-o-impacto-covid-19-enventa-online-en-mexico/

AtlantiaSearch (2020). Tendencias en canales de compra online durante la crisis. Recuperado en julio de 2020 de: https://blog.atlantiasearch.com/tendencias-encanales-de-compra-online-durante-la-crisis

Atkinson, R. y Flint, J. (2001). Accessing hidden and hardto-reach populations: Snowball research strategies. Social Research Update, 33: 1-5.

Andersen, A. L., Hansen, E. T., Johannesen, N. y Sheridan, A. (2020). Consumer Responses to the COVID-19 Crisis: Evidence from Bank Account Transaction Data, Working paper 18/20, Center for economic behavior \& inequality. http://dx.doi.org/10.2139/ssrn.3609814

Baldwin, R. y Weder di Mauro, B. (2020). Economics in the Time of COVID-19. A Vox EU.org Book, CEPR Press: Londres.

Baltar F., y Gorjup M. T. (2012). Muestreo mixto online: Una aplicación en poblaciones ocultas. Intangible Capital, 2012 - 8(1): 123-14. DOI http://dx.doi. org/10.3926/ic.294

Baker S.R., Farrokhnia R.A., Meyer S., Pagel M. y Yannelis C. (2020). How does household spending respond to an epidemic? consumption during the 2020 covid-19 pandemic. National Bureau of Economic Research. NBER Working Paper 26949.

Casero-Ripollés, A. (2020). Impact of Covid-19 on the media system. Communicative and democratic consequences of news consumption during the outbreak. El profesional de la información, 29 (2), e290223.https://doi.org/10.3145/epi.2020.mar.23

Campos, R.M. y Esquivel, G. (2020). Niveles y patrones de consumo en la era del COVID-19. Nexos, o6 mayo. Recuperado en julio de 2020de: https://www.nexos. com.mx/?p=48034.

CEPAL (2020). Intervenciones sociosanitarias y uso de las tecnologías de la industria 4.0 para enfrentar la enfermedad por coronavirus (COVID-19) en América
Latina y el Caribe, Políticas Sociales, Ed. Naciones Unidas.

Dirección General de Epidemiología (2020). Datos abiertos, Covid-19 México. Recuperado el 29 de septiembre de 2020 de: https://coronavirus.gob.mx/ datos/\#COMNac

Entrepeneur (2020). Así es como el COVID-19 ha modificado nuestros hábitos de consumo. Recuperado en julio del 2020 en: https://www.entrepreneur.com/ article/350304

García-Álvarez, L., De la Fuente-Tomás, L., Sáiz, P.L., García-Portilla, M.P. y Bobes, J. (2020). ¿Se observarán cambios en el consumo de alcohol y tabaco durante el confinamiento por COVID-19?. Adicciones. Vol. 31 (2): 85-89. https://doi.org/10.20882/adicciones.1546

Gaytán, E.D. (2020). Impacto Económico del COVID-19 en México: el necesario análisis en las cadenas regionales de suministro, El Colegio de la Frontera Norte, Departamento de Estudios Económicos. Recuperado el 30 de septiembre de 2020 de: https:// www.colef.mx/wp-content/uploads/2020/o4/ ImpactoEconomico_4-2.pdf

INEGI (2020a). Programas especiales para medición de impactos. Encuesta sobre el Impacto Económico Generado por COVID-19 en las Empresas (ECOVIDIE) 2020. Recuperado en septiembre 3o de: Recuperada en septiembre 30 de 2020 de: https://www.inegi.org. $\mathrm{mx} /$ programas/ecovidie/2020/

INEGI (202ob), Programas especiales para medición de impactos. ECOVI-ML, Encuesta telefónica sobre COVID-19 y Mercado Laboral (ECOVI-ML). Recuperada en septiembre de 2020 de: https://www. inegi.org.mx/investigacion/ecovidml/2020/

Laguna L., Fiszman S., Puerta P., Chaya C. y Tárrega A. (2020). The impact of COVID-19 lockdown on food priorities. Results from a preliminary study using social media and an online survey with Spanish consumers, Food Quality and Preference. 86. https:// doi.org/10.1016/j.foodqual.2020.104028

Mckinsey and Company (2020). Understanding and shaping consumer behavior in the next normal. Recuperado en julio del 2020 de: https://www. mckinsey.com/business-functions/marketing-andsales/our-insights/understanding-and-shapingconsumer-behavior-in-the-next-normal

Maraver-Romero, R. (2020). ¿Podría el estilo de vida mediterráneo prevenir las complicaciones derivadas de la infección por Covid-19?, Actualidad Médica,105: (809): 66-68. Doi: 10.15568/am.2020.809.admo1

Ortiz, E., Cabello, A. y Sosa, M. (2020). Financiarización y Consumismo: Multipolarismos y Crisis Covid-19. Documento de Investigación. Universidad Nacional 
Autónoma de México, Facultad de Ciencias Políticas y Sociales, Programa de Posgrado en Ciencias Políticas y Sociales. 10.13140/RG.2.2.25877.76004

Secretaria de Salud (2020). Consejo de Salubridad General declara emergencia sanitaria nacional a epidemia por coronavirus COVID-19. Recuperado el 29 de junio de 2020 de: https://www.gob.mx/salud/ prensa/consejo-de-salubridad-general-declaraemergencia-sanitaria-nacional-a-epidemia-porcoronavirus-covid-19-239301

Vergara-Castañeda, A., Lobato-Lastiri, M., Díaz-Gay, M. y Ayala-Moreno, M. del R. (2020). Cambios en el comportamiento alimentario en la era del COVID-19. Revista Latinoamericana De Investigación
Social, 3(1), 27-30. Recuperado el 20 de agosto de 2020 de: http://revistasinvestigacion.lasalle.mx/index. $\mathrm{php} /$ relais/article/view/2637

WHO (2020a). Alocución deapertura del Director General de la OMS en la rueda de prensa sobre la COVID-19 celebrada el 11 de marzo de 2020. Recuperado en junio de 2020 de: https://www.who.int/es/dg/speeches/ detail/who-director-general-s-opening-remarks-atthe-media-briefing-on-covid-19---11-march-2020

WHO (202ob).WHO Coronavirus Disease (COVID-19) Dashboard . Recuperado el 27 de junio de 2020 de: https://covid19.who.int/

Zoccolini, A. (2014). Fobia, Oriente y Occidente juntos para derrotar el miedo, 307p. , México: Ed. Trillas. 